\title{
The Development of Architectural Design Environment for BIPV using BIM
}

\author{
Eonyong Kim ${ }^{1}$, Hyunwoo Jeon ${ }^{2}$, Hanjong Jun ${ }^{3}$, Seongjoon Lee 4 \\ ${ }^{1,3}$ School of Architecture, Hanyang University ${ }^{2}$ BIMs ${ }^{4}$ Korea Conformity Labora- \\ tories \\ 1,3 \{eonyong|hanjong\}@hanyang.ac.kr2melts@naver.com4seungjoon2.lee@kcl. \\ re.kr
}

\begin{abstract}
BIPV is a building integrated photovoltaic power generation system, which is used for building finishing materials, roof, and wall, so there is no need for separate installation space, and the usability is continuously increasing in urban areas with relatively small installation space. And continues to increase. BIPV is a building-integrated type, but the application plan should be made from the early stage of design. However, there is a lack of BIPV related design information. As a result, the possibility of integrating BIPV and building design is reduced and BIPV is applied in a limited range. Method: BIM-based BIPV design process, BIPV installable location, BIPV elevation design factor. And the theory necessary to implement the support model. Lastly, usability was examined using the support model. Result: This study describes a BIM-based design support model for BIPV installed elevation design that designers can apply BIPV installation location planning and design in a BIM environment.
\end{abstract}

Keywords: Building Integrated Photovoltaic System , Building Information Modelling , Shadow Analysis , Array design

\section{BACKGROUND AND OBJECTIVE}

Building integrated photovoltaic (BIPV) systems utilized in buildings substitute exterior finishing materials in roofs and facades of buildings with a PV module; they can also be used as cladding for buildings as well as electricity producing. The BIPV system is recognized as the most suitable system for the Korean environment that lacks open areas and has numerous high-rise buildings. Meanwhile, it is difficult for architects and builders, who lack specialized knowledge, to determine the suitability of BIPV system installation, which should be reflected in the initial stages of architectural planning and design, because its performance differs considerably based on the module type, installation type, and installation conditions. A solution for this is to merge BIPV systems with building information modeling (BIM) where the sequential application is possible through programming via design criteria rather than the intuition of an architect. This is also done to gauge performance based on the analysis of surrounding external environments and empirical data of the array design and BIPV system from its initial design stage. The objective of this study is the construction of a BIM-based 
BIPV architectural design environment oriented toward architects who can creatively produce optimal BIPV design alternatives by accurately determining system suitability based on the above criteria.

\section{RELATED RESEARCH}

Building-integrated photovoltaics (BIPV) are less efficient than conventional solar photovoltaics, and studies have been conducted to find a solution to enhance the efficiency of the former. In a study focused on optimizing solar irradiation in the Hong Kong area, an investigation of the inclination and azimuth of the surface was done to achieve maximum BIPV efficiency, and BIPV installation angles and locations optimized for Hong Kong area were also presented (Fung, 2005). A similar study presented estimated annual power generation for different inclination and azimuthal angles in six major Korean cities (Seoul, Daejeon, Daegu, Busan, Gwangju, and Jeju) (Kim, 2014).

Improving BIPV efficiency by changing installation location and inclination angle have limited efficacy; thereby necessitating research on photovoltaic modules. A study verifying a module type adequate for architectural application based on analysis results of power generation performance data for a BIPV module, which was collected through an outdoor experiment on power generation characteristics by module type and installation angle, was conducted (Lee, 2016), Another research study analyzed the application status and module characteristics of BIPV systems installed in Korean public institutions in a case study (Eom, 2013).

BIPV is known to affect building appearance. To address the issue, research on semi-transparent cells has been carried out. In a study, comparison results of two modules with different transmissivities of module efficiency using semi-transparent cells showed that the module with lower transmissivity had superior power generation and thermal performance (Karthick, 2017).

One study has also been conducted in which design support software was developed for architects to lower the barrier in applying BIPVs to building design. In the study, photovoltaic system specifications and engineering and meteorological data were used to create a DB to minimize the condition input by the user and an evaluation module for the economics of photovoltaic systems based on analysis using the TRNSYS software. A developmental result of the performance analysis software for a grid-connected PV capable of BIPV integrative analysis was presented (Yoon. 2008). Another study obtained a meteorological analysis database for 162 regions in Korea and verified the validity of power generation performance for different design conditions including region, photovoltaic module type, installation location, and installation method using the existing commercial software PVsyst (Kim, 2015).

There are doubts regarding BIPV economics compared to existing photovoltaics. Research concerning BIPV economics include a study suggesting economical application methods by type with a comparative analysis of BIPV application methods available for residence type (Joh, 2006) and a study advocating the economic efficacy of BIPV through efficiency analysis of BIPV in houses (Noguchi, 2013). Another study arguing that BIPV is economical, which used the Life Cycle Cost (LCC) method to analyze the economics when BIPV was applied during the initial design stage of buildings, was also found (Bonomo, 2017).A study was found that investigated the effect of BIPV as an exterior material on building energy performance. In this investigation, a 5.25-kW BIPV installed on a building roof was monitored for its impacts on the building energy performance. Through a software simulation analysis of thermal conductivity and U-value, the study asserted that BIPV has a positive impact on the energy performance (Aaditya, 2017).

A design method to apply photovoltaics during the initial design stage of actual sites was proposed in Singapore. The design process was divided into three stages and eight design alternatives were evaluated using the Multi-Criteria Decision-Making (MCDM) method (Kosoric, 2011). A study of the de- 
Figure 1

Testbed Mock-up Building sign and application case of a zero-energy house using a photovoltaic system proposed a maintenance system optimizing building energy by applying passive design and a high-efficiency BIPV system to modify building energy load (Peng, 2017). One study developed a simplified method to readily predict the estimated amount of BIPV power generation during the design stage for different regions, module types, installation angles, azimuthal angles, and installation types (Choi, 2016).

Research on BIPV has focused on power generation efficiency and the energy efficiency of modules applied to buildings as well as analysis of power generation and economics with respect to shading, installation location, inclination angle, and azimuthal angle. However, few studies have proposed an architect-oriented BIPV system design by concretely applying the data of implementation results from shading analysis, array design, power generation prediction, and economic analysis, among other photovoltaic system design elements. It has also been shown that a feasible and reliable analysis tool applicable to a BIPV system is needed, and several studies have been in need of actual measurement data to improve BIPV system efficiency. The premises for precedent studies were module efficiency and technical challenge and calculation of power generation based on installation location in a building and module efficiency. They used various energy analytical tools capable of power generation prediction in a power generation simulation with different installation locations in a building (e.g., facade, roof, and shading shape) and installation angles and analyzed economical aspects by estimating the power generation amount. Numerous studies have been applied to actual buildings with BIPV to verify the system and data. However, a study integrating the architectural design stages for a BIPV system design is yet to be conducted.

\section{EMPIRICAL DATA COLLECTION AND BIPV LIBRARY DEVELOPMENT Testbed for data collection}

To effectively predict power generation based on various environmental variables, it was necessary to collect comparative performance data of annual solar radiation quantities from inclination angles and azimuths for each region. Subsequently, a power generation calculation and comparative analysis were conducted using environmental conditions based on meteorological data by installing a mock-up. The test bed site is installed in Seosan-si, Chungcheongnamdo, Republic of Korea. The total floor area is $210 \mathrm{X}$ and length, width, and height is $18.4 \mathrm{~m} \times 13 \mathrm{~m} \times 7 \mathrm{~m}$. The BIPV modules are installed on 5 sides on west, southwest, south, southeast, and east of the building. And the installation angles consist of $90,75,30,15$, and 3 degrees. The installed solar panel module is 120 ea which is consisted of 60ea of crystal 160w module and 60 ea of thin-film 100w. Figure 1 shows the picture of installed mock-up building and floor plan and section.
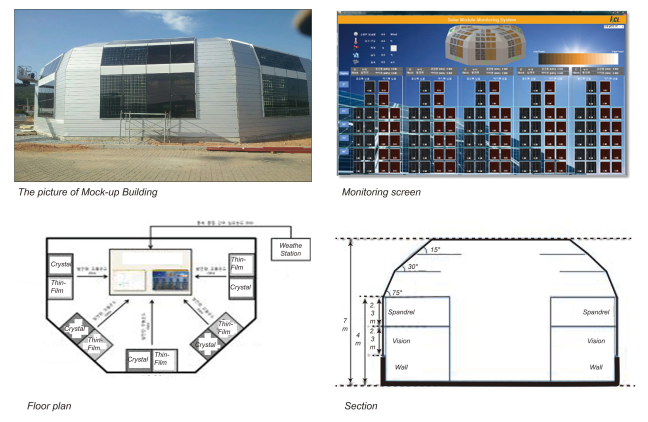

\section{BIPV Library}

The construction of a BIPV library first requires the establishment of parameter information items and parameter classification to record accurate information. In terms of an information model for the BIPV system, parameters are important factors that link correlations between the configurations of components 
and performance data extraction. The detail of the established parameters are:

- Power generation analysis: 1 . Basic calculation formula according to the basic specification of the module, and 2. Calculation formula by Mock-up data

- Economic analysis: 1. New and renewable energy supply duty ratio $=$ New and Renewable Energy Output / Estimated Energy Usage $\times 100,2$. Estimated energy usage $=$ total building area $\times$ unit energy consumption, 3. Correction factor by application $\times$ Area coefficient, 4. New and renewable energy production volume $=$ installation scale by source $\times$ Unit energy, 5 . Production amount $\times$ correction factor, 6 . Break-even point calculation (initial investment cost, annual power generation cost, and 7. Cost of replacing exterior materials, cooling/heating energy cost per year.

- BIPV installation basic rules: Installation Specifications

- Legal review: 1. New Energy and Renewable Energy Development Promotion Act, and 2. Regulations on support for renewable energy facilities, etc.

- Solar cell characteristics information: Module test report, module specification information, and supplementary material specification information

- System Integration Company Information: 1. Model name, manufacturer, manufacturer's phone number, manufacturer URL, and module insulation configuration, and 2. Frame configuration, and installation cost

- Materials and Finishes: Glass material and frame material

- Module Information: Characteristics, function, application, product shape, test report, and module product price

- Building performance: Power generation, efficiency, module configuration, specification of auxiliary materials, heat transfer rate, permeability, and details an Information
- Size: Vertical bar Vertical length, and vertical bar thickness

- Estimation Factor: Material cost, labor cost, and unit cost

- Material Information: Module insulation construction, double layer glass design, and Frame composition

Using the established parameters, a construction library was built with a G-to-G type multi-stage module that accounts for the majority of the BIPV systems, as well as two types of PV-crystalline structure (c-Si) and thin film (a-Si). Subsidiary materials constructed one type of module frame, six types of inverters, and eight types of connection bands. A BIPV library not only improves work efficiency and reliability among architects through the automation of company, performance, and estimate information, but can also reflect changing the information in real time. Figure 2. shows the libraries of the modules which has 3D model, elevation, and plan.

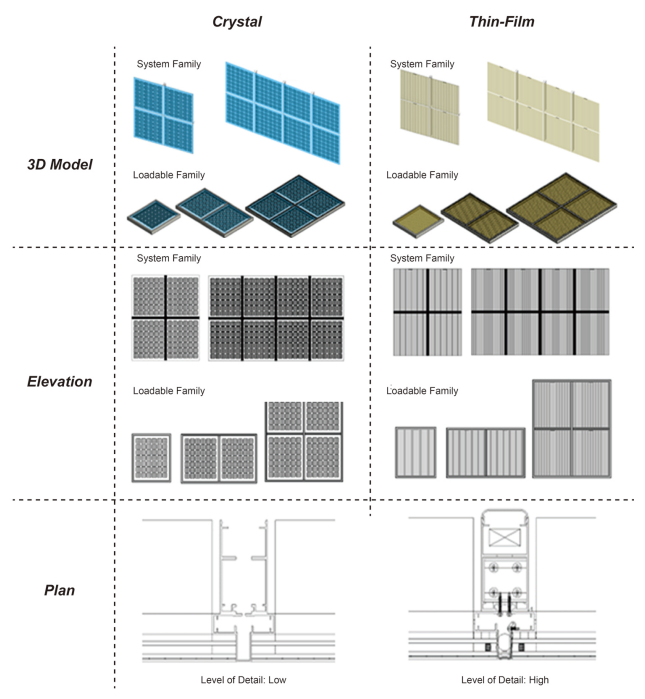

Figure 2 BIPV module library 
Figure 3

Initial screen of BIM-based BIPV design application

Figure 4 Structure of the program
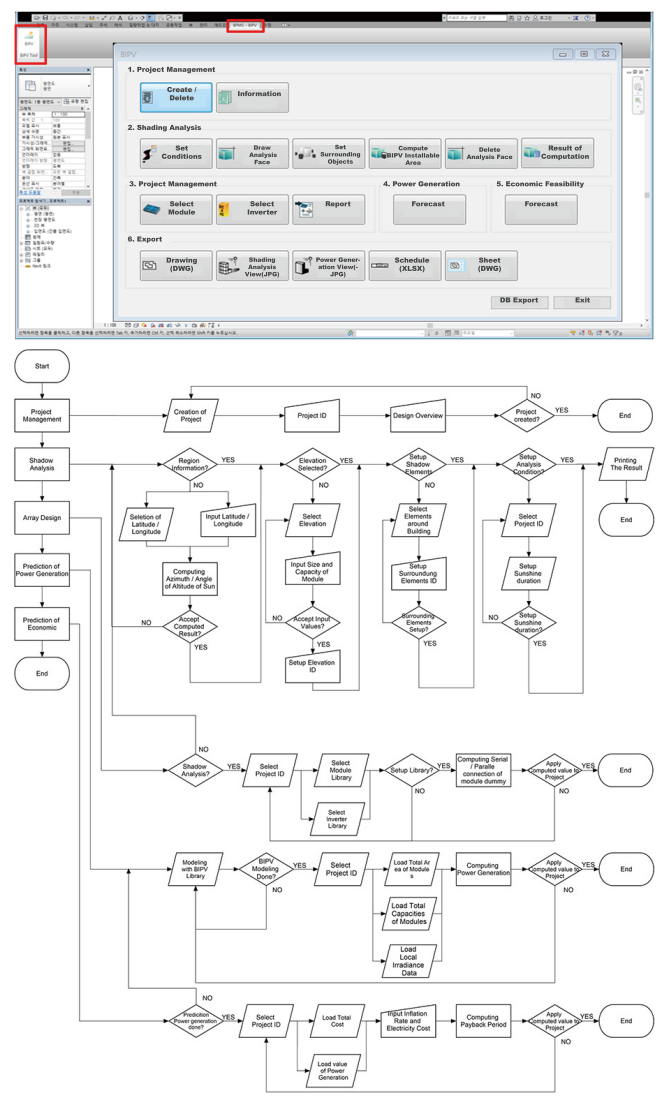

\section{DEVELOPMENT PROGRAM OUTLINE}

In this research, BIM environment means using Autodesk Revit SDK. On the environment, the program for BIPV design support is developed with API supported by Autodesk. The program runs in the Revit 2008 and 2009 as add on program. The purpose of program is to support discover the optimal alternative of BIPV design for architectural designer with various information related BIPV.

The program can output the calculation results by directly extracting the data needed from the BIM model, systemizing BIPV material information, con- structing digital material information, and improving reliability by connecting a prospective calculation algorithm from empirical solar radiation data. This program was developed by employing a shading analysis, an array design, power generation forecasts, and economic feasibility analysis algorithms. This provides meteorological data analysis, a PV design analysis, an analytic forecast, and a document creation function of the buildings targeted for design. Further, the analytic and forecasting function provides a shading analysis, an array design, and power generation and economic feasibility forecasts. Figure 4. shows the structure of the program and Figure 3. shows the initial screen of the program.

Until the simulation is finished, the results of each function remain in the memory and then the result of the simulation is stored as a database file. The result can be converted to report with the database file and stakeholders can share the result with the reports easily.

The test building for the program test is newly built testing facility in Chungbuk Innovation City in Korea. BIPV system, which is $33.652 \mathrm{~kW}$ of capacity, thin-film and crystal module, is planned to install on the building.

\section{Shading Analysis}

One of the important factors in BIPV power generation performance is shading in the building surface. The shading analysis analyzes shading related sun movement, surrounding buildings, terrains. The using analysis method in the program applies the current solar view analysis technique to compute shading occurrence on the face of the target building. The shading analysis runs using to calculate the angle of altitude and azimuth of the sun, coordination of azimuth quadrant, and projection of the object

Setting elevation is required to analyze the BIPV possible installation area. In this step, The building faces general module size and faces grid is set and then the duration of sunshine is set as an analysis condition. After finish building elevation setting, surrounding objects should be set. Figure 5 . shows ana- 
lytical surface settings. In this setting, the parameters of the module can be set and the surface to analyze shading can be selected.

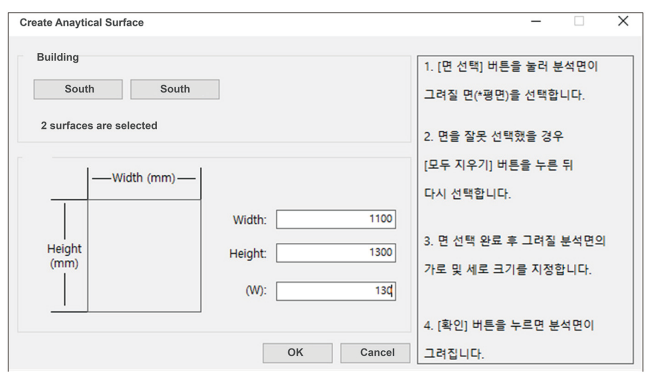

In this program, the surrounding objects are neighborhood buildings. The buildings are called to Building 1 to building $\mathrm{n}$. The shading elements converted to $x, y, z$ coordination with the quadrant coordination convert formula. BIPV installation possible analytical surfaces are displayed with grid lines. If the color of grid lines is red, it means before analysis, unsatisfied to installation condition, or the faces are influenced by surrounding environments. If the color of the grid lines is green, it means the installation condition is satisfied. Figure 6 . shows the visual result of shading analysis.
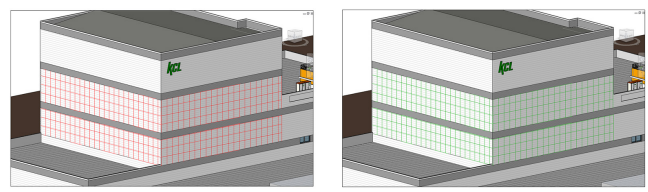

\section{Array Design}

An architectural designer can decide BIPV installation capacity according to client's requirements using the array design. In this phase, the type of BIPV module, inverter, and connection board can be decided. The BIPV elevation design must be invoked complex factors which are the result of the shading analysis. If the relations with electrical properties of module and inverter is not calculated properly, dummy modules for only elevation design can be issued. The dummy modules don't generate power and the more dummy module the less power generation and economic feasibility. This program can help to arrange modules in the serial and parallel placement of modules optimally. The calculation of the serial and parallel placement of modules uses the formula of temperature anomaly on the surface of modules, the capacity, and voltage of module and inverter. the used formulas are:

$$
\begin{aligned}
& t_{\max d}=25-t_{\max } \\
& t_{\min d}=25-t_{\min } \\
& \text { where, }
\end{aligned}
$$

$t_{\max d}$ : Max temperature anomaly of modules $t_{\min d}$ : Min temperature anomaly of modules $t_{\text {max }}$ : Max temperature of target location $t_{\text {max }}$ : Min temperature of target location

$$
\begin{aligned}
& N_{S \text { max }}=\frac{V d c}{V o c} \times\left\{1+\left(V_{n t} \times t_{\min d}\right)\right\} \\
& N_{S \text { min }}=\frac{V d c m}{V m p p} \times\left\{1+\left(V_{o t} \times t_{\min d}\right)\right\}
\end{aligned}
$$

where,

$N_{S} \max :$ Max number of serial modules

$N_{S \text { min }}$ : Min number of serial modules

$V_{n t}$ : Temperature factor of normal voltage of module

$V_{o t}$ : Temperature factor of operation voltage of module

$V d c:$ Inverter max input voltage

$V d c m$ : Inverter min input voltage

$V$ oc: Module normal voltage

$V m p p$ : Module operation voltage

$$
N_{P}=\frac{C_{I}}{N_{S} \times O_{M \max }}
$$

where,

$N_{P}$ : Number of parallels modules

$C_{I}$ : Inverter capacity

$N_{S}:$ Number of serial modules

$O_{M}$ max : Max output of module

Figure 7. shows the screen of the setup module setting. in this screen, the thin-film module is selected and the detail specification of the selected
Figure 5

Analytical surface settings

Figure 6

The result of shading analysis: left is unsatisfied, right is satisfied 
Figure 7

Setup module settings

Figure 8

Setup inverter settings

Figure 9

Array Design Report

Figure 10

The result of forecasting power generation module can be checked. And Figure 8. shows the setup inverter setting. the selected inverter is transformer type and three phases $100 \mathrm{kw}$ (independence indoor). in the part, the detail specification can be referenced. The serial and parallel array analysis brings out the installation capacity, cost, BIPV production power amount, forecasting energy consumption amount, the duty ratio of green energy in the report. Figure 9. shows the array design report.
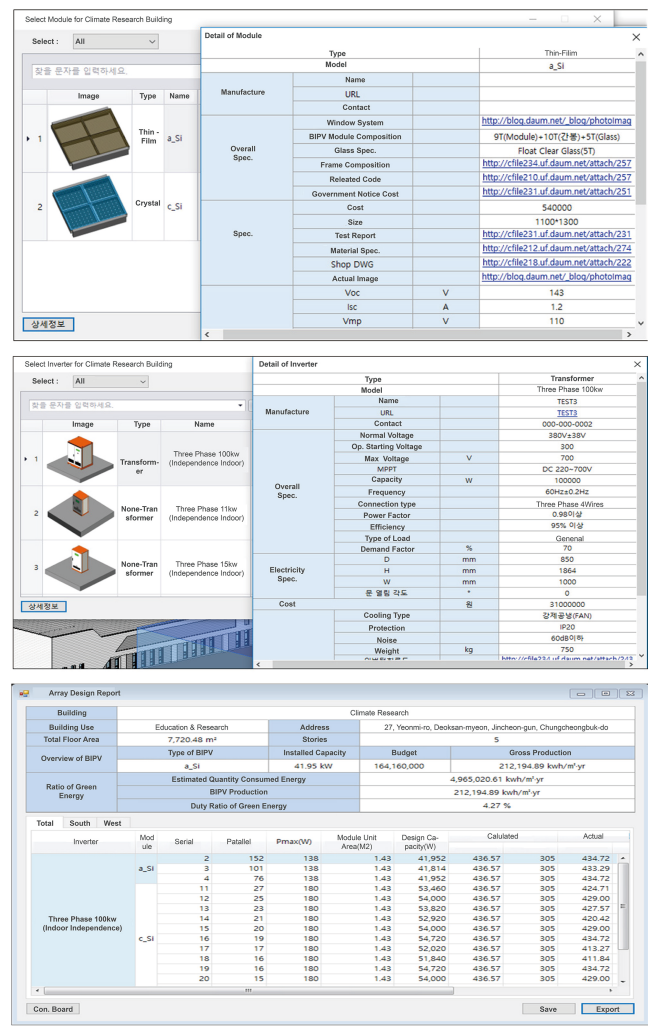

\section{Forecasting power generation}

The decision of BIPV location for BIPV maximum power generation is required analysis and construct data of yearly accumulated irradiation gain perfor- mance comparison on the angle of altitude and azimuth of the sun. To do it, the mock-building is used as mentioned in previous. At the mock-up building, the values of Isc, Voc, Pmax, Vpm, Ipm, and FF of modules and irradiation, humidity, temperature, wind direction, and wind speed are measured and stored into the database daily. Figure 10. shows the result of forecasting power generation. With the data the formula of forecasting power generation is made:

$$
E_{P M e}=P_{A M} \times\left(\frac{H_{A M}}{G_{S}}\right) \times K \times A
$$

where,

$E_{P M e}$ : Forecasting power generation by the empirical irradiation

$P_{A M}:$ Total installed area $\left(m^{2}\right)$

$H_{A M}$ : Monthly or Yearly accumulated irradiation $\left(\mathrm{kWh} / \mathrm{m}^{2} \cdot\right.$ month or year)

$G_{s}$ : intensity of solar radiation $\left(\mathrm{kWh} / \mathrm{m}^{2}\right)$

$K$ : Module efficiency(Tested average efficiency) $A$ : Modification Factor( 0.78 applied)

$E_{P M s}=P_{A M} \times$ hour $\times$ day $\times K[k W h]$ where,

$E_{P M s}$ : Forecasting power generation by the standard test condition

$P_{A M}$ : Total capacity of modules $[k W]$

hour: Power generation hour(applied 3.4 hours per day)

day: Power generation days(30 days per month, 365 days per year)

$K$ : Module efficiency(average efficiency of the test grade)

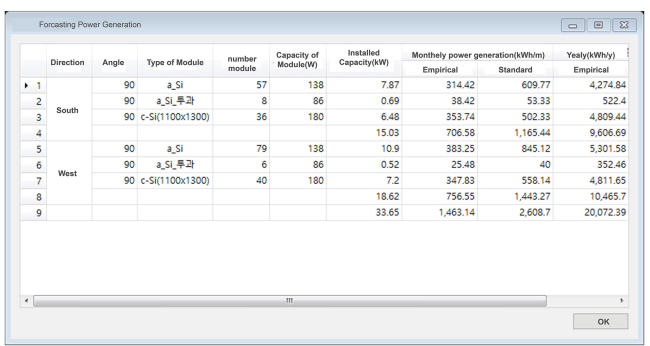

Figure 9. shows the result of forecasting BIPV power 
generation. In the forecasting, the properties of BIPV installation are 90-degree installation and installation on the south and west face of the building. The result shows monthly and yearly forecasting power generation in empirical irradiation base(equation 6) and standard test condition base(equation 7) by installation degrees, directions, and type of module.

\section{DISCOVER DESIGN ALTERNATIVES}

The developed program is tested in a practical design and construction project to apply BIPV. The project is façade renovation of Wolgae middle school which is located in Seoul, Korea. This project is part of the business to renovate façade of old school building ordered by Seoul metropolitan of education, Korea. During this test, the program has been tested from design to construction. The requirements of the business are focusing on the aesthetic aspect of school building so using the conventional solar module is not satisfied with the requirement. To meet the business requirement, the color solar module is required so the BIM library of the color module is modeled.

The target buildings for this project are the main building and sports center originally but the sports center was canceled after the simulation phase. Three façade design alternatives were created for the main building and the optimal design alternative was selected with consideration BIPV performance. The result of simulation shows the south face of the main building is the optimal direction to install BIPV with $756.49 \mathrm{~m}^{2}$ possible installation area, 520ea modules, and $52.9 \mathrm{~kW}$ possible installation capacity. In comparison, north façade doesn't have possible installation area, east façade has $71 \%$ of capacity, west façade has $24 \%$ of capacity against south façade. In Figure 11. the detail is described.

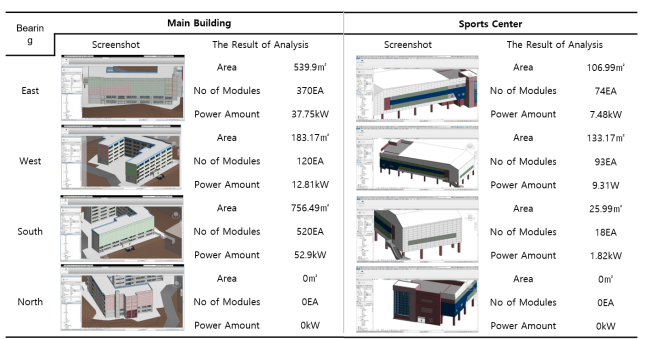

The three façade design alternatives were shown in Figure 12. The alternatives 3 was selected as the optimal alternative because the amount of power generation is $16.6 \mathrm{kWh}$ and the total annual amount is $18.067 .5 \mathrm{kWh}$. The power generation of alternative 3 is $6 \%$ bigger than alternative 1 and $42 \%$ greater than alternative 2 .
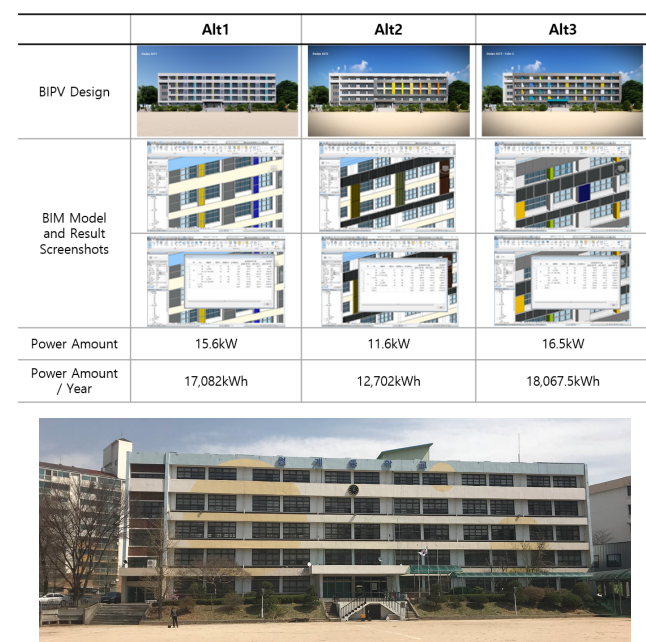

Before facade renovation

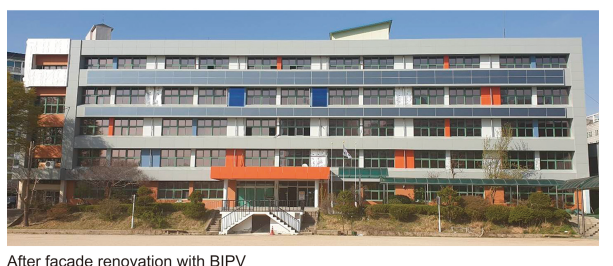

Figure 11

The result of simulation of Wolgae middle school

Figure 12

Design alternatives for Wolgae middle school main building

Figure 13

The comparison of before and after renovation 
After the design phase, the construction with the optimal design has done actually. Figure 13 . shows before and after the renovation of the building façade. It is one example of using color modules for BIPV.

\section{CONCLUSION}

Using a BIPV library based on the developed BIM, it is possible to automatically calculate installation capacity, initial investment costs, renewable energy output, and expected energy usage during BIPV design. Even architects with no experience can predict power generation based on various installation conditions and can quickly and simply determine system suitability in the design stage. In the BIM model, the solar radiation results of the standard test condition theoretical equation and the power generation comparison results of installation angle and installation direction using solar radiation field measurements showed an average error rate of $21 \%$. Further, based on the incline, errors observed were higher for vertical predictions compared with horizontal predictions. Accurate quantity estimation based on a BIPV library that uses BIM produces accurate baseline data. Order management for primary resources and materials is possible using BIM, and this can be connected to job site processes and managed.

\section{ACKNOWLEDGMENT}

This work was supported by the Korea Energy Agency(KEA) (No. 71000151), the Korea Institute of Energy Technology Evaluation and Planning(KETEP) (No. 20173010013680) and the Ministry of Trade, Industry \& Energy(MOTIE) of the Republic of Korea.

\section{REFERENCES}

Aaditya, G and Mani, M 2016, 'BIPV:a real-time guilding performance study for a roof-integrated facility', International Journal of Sustainable Energy, 37(3), pp. 249-267

Bonomo, p, Frontini, F, De Beradinis, P and Donsate, I 2017, 'BIPV:building envelope soulutions in a multicriteria approach. A method for assessing life-cycle costs in the early design phase', Advances in Building Energy Research, 11(1), pp. 104-129
Choi, WK 2016, 'The Simplified Pre-Estimation Model Development of a BIPV Generation Rate by the District Division', Journal of the Korea Solar Energy Society, 36(2), pp. 19-29

Eom, JY 2013, 'The Status Analysis of BIPV System Module in Public Buildings Based on Obligation System of New \& Renewable Energy,', Journal of the Architectural Institute of Korea(Planning \& Design), 29(4), pp. 259-266

Fung, TYY and Xing, YH 2005, 'Study on Optimum Inclination Angle of Solar Collecting Surface in Hong Kong', HKIE Transactions, 12(1), pp. 44-48

Jeong, SJ 2016 'A Study on the Application of BIM for the Design of BIPV System', Proceedings of Korea Institute of Construction Engineering and Management

Joh, H 2006, 'A Research on Building Integrated Photovoltaic System as Architectural Design Element in Residential Building Type', Journal of the Architectural Institute of Korea(Planning \& Design), 22(8), pp. 109-118

Karthick, A, Kalidasa Murugavel, K, Kalaivani, L and Saravana Babu, U 2017, 'Performance study of building integrated photovoltaic modules', Advances in Building Energy Research, 12(2), pp. 178-194

Kim, DS 2014, 'Annual energy yield prediction of building added PV system depending on the installation angle and the location in Korea', The International Journal of The Korea Institute of Ecological Architecture and Environment, 14(1), pp. 67-74

Kim, BJ 2015, 'The Development of Performance Evaluation Program of Building Integrated Photovoltaic System', Korea Institute of Ecological Architecture and Environment Journal, 15(4), pp. 85-90

Kosoric, V, Wittkopf, S and Huang, Y 2011, 'Testing a design methodology for building integration of photovoltaics (PV) using a PV demonstration site in Singapore', Architectural Science Review, 54(3), pp. 192205

Lee, EB 2015, 'A Study on the Implementation Method of the Object Classification System and Property Information for Vitalizing Standardized BIM', Journal of the Architectural Institute of Korea(Planning \& Design), 31(12), pp. 79-90

Lee, SM 2016, 'A study on the performance of various BIPV modules applied in a real building demonstration', Journal of the Korean Solar Energy Society, 36(2), pp. 53-63

Lee, SY 2017, 'A Study on BIPV(Building Integrated Photovoltaic) Design Process based on the BIM(Building Information Modelling) for Architects', Journal of the Architectural Institute of Korea(Planning \& Design), 
33(4), pp. 49-57

Noguchi, M 2013, 'Calibrating air heating and power generation capacities of low and high efficient BIPV roofs for housing application in Scotland', International Journal of Environmental Studies, 70(6), pp. 987-998

Peng, C, Huang, L, Liu, J and Huang, Y 2015, 'Design and practical application of an innovative net-zero energy house with integrated photovoltaics: a case study from Solar Decathlon China 2013', Architectural Science Review, 58(2), pp. 144-161

Yoon, JH 2008, 'Software Development on Power and Economic Analysis of Photovoltaic System for Building Application', Journal of the Architectural Institute of Korea(Planning \& Design), 28(1), pp. 1-8

Yoon, KC 2012, 'Comparative Analysis of Measurements and Total Solar Irradiance Models on Inclined Surface for Building Solar Energy Prediction', Journal of the Korean Solar Energy Society, 32(6), pp. 44-52 